\title{
Digital accessibility: A systematic Literature Review
}

\author{
Fatima Ezzahra Chadli ${ }^{1 *}$, Driss Gretete ${ }^{1}$, and Aniss Moumen ${ }^{1}$ \\ ${ }^{1}$ Engineering Sciences Laboratory, National School of Applied Sciences, Ibn Tofail University, \\ Kenitra, Morocco
}

\begin{abstract}
Today digital content has soared since the covid19 pandemic, no physical interaction, only digital operations, even in the education system and training. Learning moved towards the virtual classroom, and elearning is now widely adopted. This transformation was a challenge for most people, especially people with disabilities. Although, despite the type of disability, digital content and services should be accessible, which means it includes considerations like compatibility with assistive technologies, using enough contrast for visually impaired users, providing understandable content, etc. Many studies have shown decades before covid19 the importance of digital accessibility, including guidelines, implementation and evaluation, design and methods. This systematic literature review of 204 studies exposes the different topics related to digital accessibility in previous studies.
\end{abstract}

\section{Introduction}

"The power of the web is in its universality. Access by everyone regardless of disability is an essential aspect", this is a famous quote by Tim Berners-Lee, director and inventor of the World Wide Web [1]. As defined by World Wide Web Consortium (W3C) [2] and Web Accessibility Initiative (WAI) [3], Digital accessibility means that people with disabilities should be able to access, navigate, perceive, and interact with content [4]. However, people with disabilities (PWD) still face many challenges and difficulties with digital content.

COVID19 might be an evident example that emphasizes those serious barriers that disabled people face every day. Digital content has soared since the COVID19 pandemic, with no physical interaction, only digital operations. This transformation and quick switch to fully digital services was a challenge for most people, especially people with disabilities who are less comfortable than others using certain technologies [5].

Disability involves one or more impairments, including visual, physical, mental, cognitive, hearing or speech impairment. International guidelines include norms and standards to cover different impairments. Most of the policies use the Web Content Accessibility Guidelines (WCAG) [6], proposed by W3C via the Web Accessibility Initiative (WAI) [3].

${ }^{*}$ Corresponding author: fatimaezzahra.chadli@uit.ac.ma 
This article covers five sections; besides a general introduction, we overview the WCAG standards, describe our systematic literature review SLR and expose its main results. The last section presents discussions and conclusions.

\section{Overview of WCAG}

\subsection{WCAG History}

WCAG are standards and norms that explain how to make accessible content for people with disabilities [6].

The first version WCAG1.0 [7], was published in 1999 and was focused on HTML. It was followed in 2008 by WCAG2.0 [8]; this second version was focused on new digital assets besides HTML as texted documents and more technologies not covered by WCAG1.0 and integrated four principles. In 2018 a new version, WCAG2.1 [9], was published and added many criteria and was approved as an ISO standard.

The new latest version, WCAG2.2 [10], is set to publish in 2021. WCAG works with a backwards-compatible principle, meaning that content that meets the new version should meet the previous one [6].

\subsection{Four principles of accessibility (POUR)}

WCAG guidelines focus on four principles of accessibility; perceivable, operable, understandable and robust (POUR) [11]:

-Perceivability: The user must perceive content and components, providing text alternatives for non-text content and audio description or media alternative for time-based media [12].

-Operability: the user must interact easily with the content, all functionalities must be accessible via keyboard, providing enough time to read and use the information [13].

-Understandability: The user must understand information and operation as clear and familiar word, indication about the language, the meaning of the provided abbreviation, and more other criteria [14].

-Robustness: compatibility with various user agents, browsers, devices and assistive technologies [15].

\section{SYSTEMATIC LITERATURE REVIEW}

\subsection{Methodology}

Our methodology is based on a systematic literature review (SLR) to identify prior research and studies relative to digital accessibility for all disabilities without specifying any limitation or criteria for impairment. To conduct our SLR, we followed the steps below [16]:

1. We determined the keywords for research: Digital Accessibility, Web Accessibility, people with disabilities, impairment, universal design, WCAG. We combined operators "AND", "OR" with keywords and adapted search strings to each scientific database: Springer Link, Web of Science, Scopus, Science Direct, Cairn, IMIST and Google Scholar. 
2. We selected results based on inclusion and exclusion criteria, and we removed duplicate studies.

3. We selected results (204 articles) finally and analyzed them using NVIVO software.

The following figure illustrates the different steps:

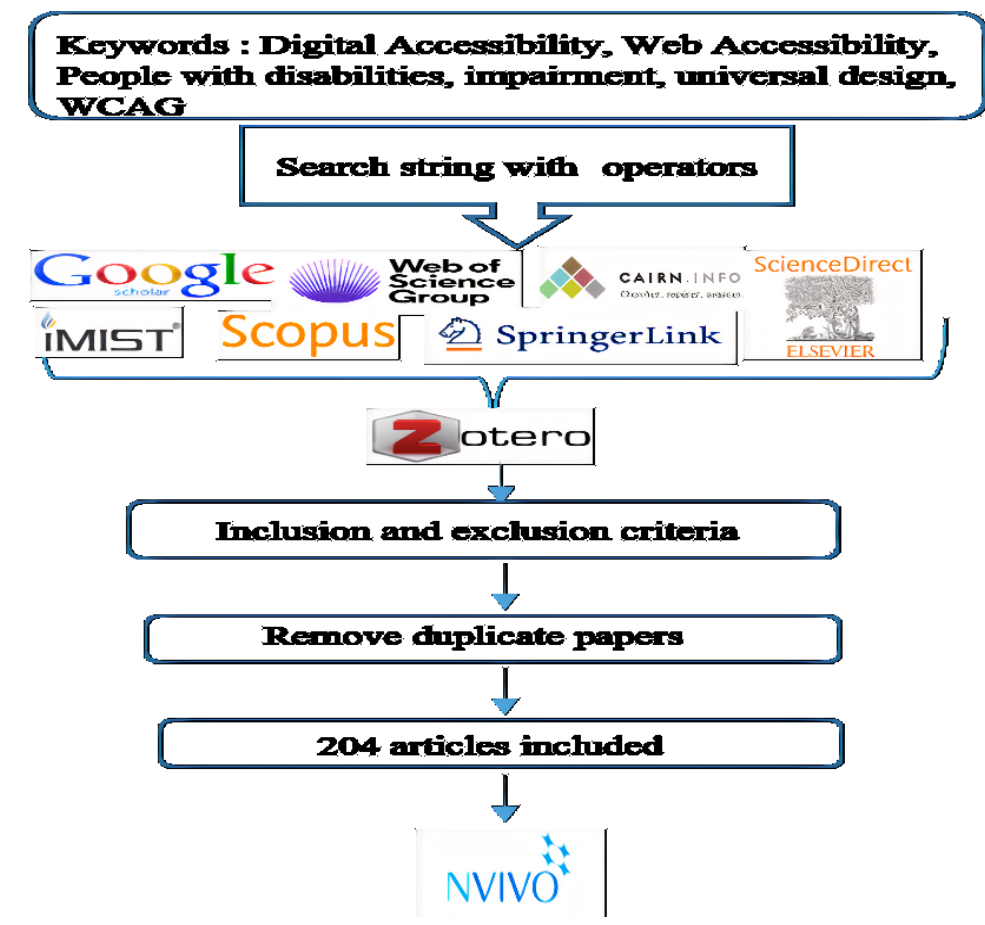

Fig. 1. Systematic Literature Review methodology

\subsection{Meta-analysis}

\subsubsection{Reference Analysis}

Table 1 below summarizes the types and frequency of references used in our selection. Journal articles represent $86.8 \%$ of selected references, followed by conference papers with $6,4 \%$ and books with $4.9 \%$, chapters represent only $2 \%$ of our selection.

Table 1. Types of references and frequency.

\begin{tabular}{|c|c|c|}
\hline Types of references & Frequency & Per cent \\
\hline Article & 177 & 86,8 \\
\hline Book & 10 & 4,9 \\
\hline Chapter & 4 & 2,0 \\
\hline Conference Paper & 13 & 6,4 \\
\hline Total & 204 & 100,0 \\
\hline
\end{tabular}


For source information, Table 2 below shows the score assigned to each scientific database used. The results show that Springer link obtained the highest score with 55,88\%, followed by Science Direct with $12,25 \%$, Google Scholar with $11,27 \%$, Web of Science $8,82 \%$, Cairn $6,37 \%$, Scopus 3,92\% and IMIST with $1,47 \%$.

Table 2. Distribution summary of a scientific database

\begin{tabular}{|c|c|}
\hline Scientific Database & Per cent \\
\hline Springer Link & 55,88 \\
\hline ScienceDirect & 12,25 \\
\hline Google Scholar & 11,27 \\
\hline Web of Science & 8,82 \\
\hline CAIRN & 6,37 \\
\hline Scopus & 3,92 \\
\hline IMIST & 1,47 \\
\hline
\end{tabular}

We identified five periods ([2000-2004],[2005-2009], [2010-2014], [2015-2019], [20202024]) with a span of 4 years to simplify analysis for included references, as shown in Figure 2 below:

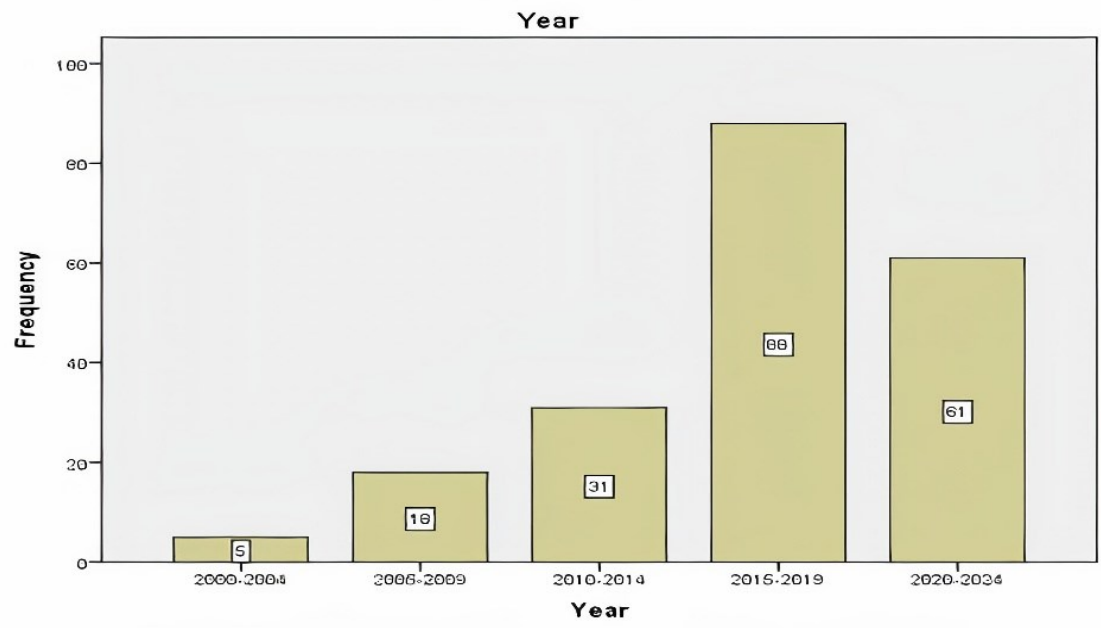

Fig. 2. Frequency and period of publication.

The bar graph shows that the highest frequency is between 2015 and 2019, which could be interpreted by adopting the first sub-version of WCAG2 in 2018, namely WCAG 2.1. The period between 2020 and 2024 ranked second with 61 references due to the context of covid19.

For the distribution of included references by language, we note that 183 references corresponding to $89,7 \%$ is in English and 21 references corresponding to $10,3 \%$ is in French. 
Table 3.Frequency of references by language

\begin{tabular}{|c|c|c|}
\hline Language & Frequency & Per cent \\
\hline English & 183 & 89,7 \\
\hline French & 21 & 10,3 \\
\hline Total & 204 & 100,0 \\
\hline
\end{tabular}

\subsubsection{Word analysis}

Word analysis or word cloud shows a visual representation of the most words used in our references. The size of each word depends on its frequency. The most used words include accessibility, disabilities, web and Learning; we can also notice that visual impairment is the most used type of disability within the selection; we note that we included all types of disabilities without limitation or specification of impairment.

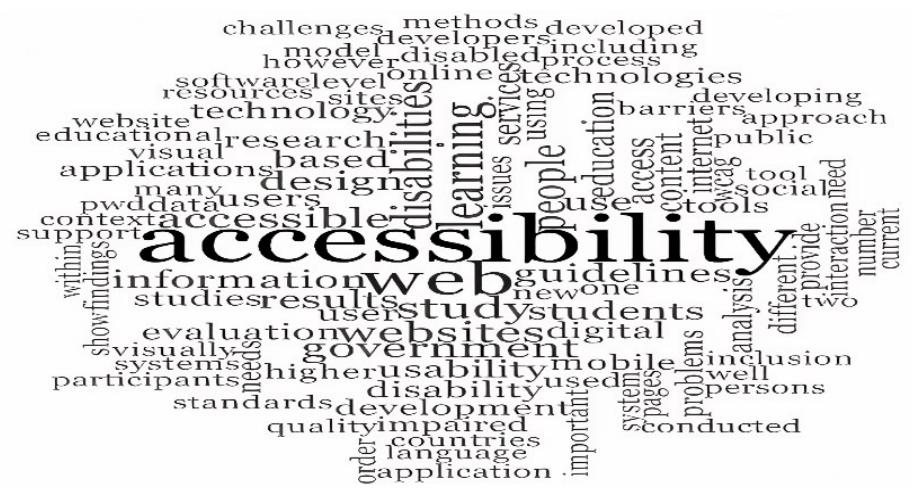

Fig. 3. Word analysis.

\section{RESULTS}

\subsection{Disability in Morocco}

In 2014, a national survey was conducted in Morocco, including a sample of 47275 participants representing 16044 households from urban and rural areas; according to this survey disability, the prevalence rate is $6.8 \%$, about 2.264 .672 . One family out of four has at least one person with a disability. As shown in Table 4 below; People with one disability represent $4,45 \%$, people with two disabilities represent $1,6 \%$, and people with three disabilities or more represent $0,75 \%$ [17]. 
Table 4.Prevalence by number of disabilities according to the national survey [17]

\begin{tabular}{|c|c|c|}
\hline Number of disabilities & Person & Per cent \\
\hline One disability & 1.482 .028 & 4,45 \\
\hline Two disabilities & 532.864 & 1,6 \\
\hline Three or more disabilities & 249.780 & 0,75 \\
\hline Total & 2.264 .672 & 6.8 \\
\hline
\end{tabular}

As shown in Table 5 below, the prevalence varies according to the type and level of disability:

Table 5.Prevalence by type and level of disabilities according to the national survey [17]

\begin{tabular}{|c|c|c|c|}
\hline Type of disability & $\begin{array}{c}\text { Mild to } \\
\text { moderate }\end{array}$ & Very Severe & $\begin{array}{c}\text { Mild to very } \\
\text { severe }\end{array}$ \\
\hline Vision & $3,47 \%$ & $0,10 \%$ & $3,56 \%$ \\
\hline hearing & $0,91 \%$ & $0,09 \%$ & $0,99 \%$ \\
\hline Mobility & $3,07 \%$ & $0,27 \%$ & $3,34 \%$ \\
\hline Memory & $0,65 \%$ & $0,10 \%$ & $0,75 \%$ \\
\hline Personal care & $0,66 \%$ & $0,21 \%$ & $0,87 \%$ \\
\hline Communication & $0,53 \%$ & $0,16 \%$ & $0,69 \%$ \\
\hline
\end{tabular}

As reported in the survey, visual and mobility impairment is the most common within Moroccan disabilities.

\subsection{Digital accessibility in Morocco: government initiatives}

Morocco has engaged in a digital strategy in 2013, called digital Morocco 2013, for public administration modernization. Among its notable results is the common charter for governmental websites [18]; this document makes 18 pages including norms and standards to respect governmental websites, as the minimum sections to include in a website, structure and components of the website, and the language used and accessibility recommendations. The accessibility part of the charter is not obligatory; it is recommended to implement by departments. Table 6 below provides a synthesis of those recommendations:

Table 6.Accessibility recommendation in the charter for governmental websites

\begin{tabular}{|c|c|}
\hline Component & Recommendation \\
\hline Graphic elements & Each graphic element must have a textual alternative \\
\hline Displays & $\begin{array}{c}\text { The weight of the web pages must be about 300ko per page to allow } \\
\text { rapid display and ensure a quality user experience }\end{array}$ \\
\hline Readability & The user should be able to resize the text \\
\hline Responsive design & $\begin{array}{c}\text { Websites should be adapted to mobile navigation, especially for the } \\
\text { home page, links for Administrative Procedure and services }\end{array}$ \\
\hline
\end{tabular}


We notice that the charter not fully covers all the aspects, standards and norms of accessibility; it integrates just a few recommendations and issues about web accessibility.

\subsection{Digital accessibility: Moroccan studies}

Concerning research studies, we notice that Moroccan researchers have conducted few works in digital accessibility that we divided into two categories; topics related to egovernment and others related to education:

* Accessibility and e-government :

The authors [19] conducted research based on the evaluation of three Moroccan egovernment websites accessibility using AccessiWeb methodology created by the BrailleNet Association to detect accessibility problems and check the conformity with the Accessibility Initiative Guidelines WCAG. The authors established an evaluation grid with thirteen thematics: images, frames, colours, multimedia, tables, links, scripts, mandatory elements, the structure of information, presentation of information, forms, web pages consultation and navigation. Tests used automatic tools, and for the three evaluated websites, the minimum level A of accessibility is not respected. There are various measures [19] to take for each principle of accessibility, as shown in Table 7 below:

Table 7.Measures recommended by I. Bousarhane and N. Daoudi [19] to meet the four principles of accessibility for the three evaluated websites:

\begin{tabular}{|c|c|}
\hline Principle & Recommendation \\
\hline Perceivability & $\begin{array}{l}\text {-Provide text equivalents for non-textual items, } \\
\text {-Increase the contrast ratio, make time-based media identifiable } \\
\text {-Provide summaries and titles for tables. } \\
\text {-Make all links explicit } \\
\text {-Indicate changes of reading direction in the source code } \\
\text {-Organize the content by the use of titles. } \\
\text {-Use CSS, associate form fields with relevant labels } \\
\text {-Offer accessible versions to documents for download and make } \\
\text { it possible for users to control flashing contents }\end{array}$ \\
\hline Operability & $\begin{array}{l}\text {-Make the control of time-based media and no time-based media } \\
\text { possible by the keyboard, } \\
\text {-Give pertinent titles for } \\
\text { links and web pages, } \\
\text {-Make explicit links that open in a new window, } \\
\text { - Add links that help bypass the blocks of content and the groups } \\
\text { of links, provide information about the documents for download, } \\
\text {-Ensure that navigation does not contain keyboard traps and that } \\
\text { the sitemap page shows the general architecture of the website. }\end{array}$ \\
\hline Readability & $\begin{array}{l}\text {-Integrate explicit buttons to initiate context changes. } \\
\text { Indicate Language changes in the source code. } \\
\text {-Append the labels associated with form fields with their fields, } \\
\text { Indicate mandatory fields } \\
\text {-Display suggestions for the input control that facilitate the } \\
\text { correction of errors. }\end{array}$ \\
\hline Robustness & $\begin{array}{l}\text {-Provide for each framework used a relevant title. } \\
\text {-Provide equivalent alternatives. } \\
\text { - Make all media compatible with assistive technologies. } \\
\text { - Define the type of each document so that assistive technologies } \\
\text { could render hidden texts. } \\
\text {-Provide an appropriate title for each form button. }\end{array}$ \\
\hline
\end{tabular}


* Accessibility and education:

The authors [20] focused on m-learning or mobile Learning for students with disabilities; they exposed the problems faced by this particular category of students with assistive technology AT due to many factors such as affordability and availability. The authors used quantitative and qualitative methods to compare seven AT devices and seven alternative open-source medical apps for students with hearing impairment, visual impairment, autism and speech articulation disorder. The study findings have thus proved that open source applications are efficient alternatives to monofunctional AT devices in formal and informal learning environments.

The authors [21] discussed the importance of mobile Learning in university for people with disabilities, especially motor disabilities. The authors used quantitative and qualitative methodology; data collection concerns a sample of the population that represents 40 students with disabilities in Med V University Rabat. The study findings have revealed that mobile technologies can foster student engagement and participation and increase their interactions.

\subsection{Digital Accessibility: International studies}

Digital Accessibility is a vast field; some authors have followed a targeted approach to study and research specific components instead of looking for digital accessibility in all its aspects.

We identified 19 studies in our SLR that targeted specific components in digital accessibility; below; we summarize the results with the relevant studies:

\section{* Studies on search engine component}

The authors $[22,23]$ focused on the search engine as an essential component for searching information and proposed in their studies interactive tools to improve the interactive experience with the search engine. The authors [23] described a prototype search engine that provides a re-ranked set of search results.

\section{* Studies on Chabot component}

The authors [24-26] highlighted the importance of chat applications and conversational agents to enhance the learning experience for students with disabilities. The authors [24] Have compared the three most-used non-commercial learning content management system CMS, namely Moodle, Edmodo, and Instructure. The authors have provided recommendations to improve and build inclusive chat applications; the study showed that Moodle includes features that avoid accessibility barriers. The authors [25] Focused on educational chatbots for Facebook Messenger to support Learning and examined their quality based on language, subject and development platform and presented a list of the top ten educational chatbots. Liu Qingtang \& al [26] proposed an agent-based conceptual architecture to develop a domain-specific Chabot for mobile Learning, as shown in figure 4 below: 


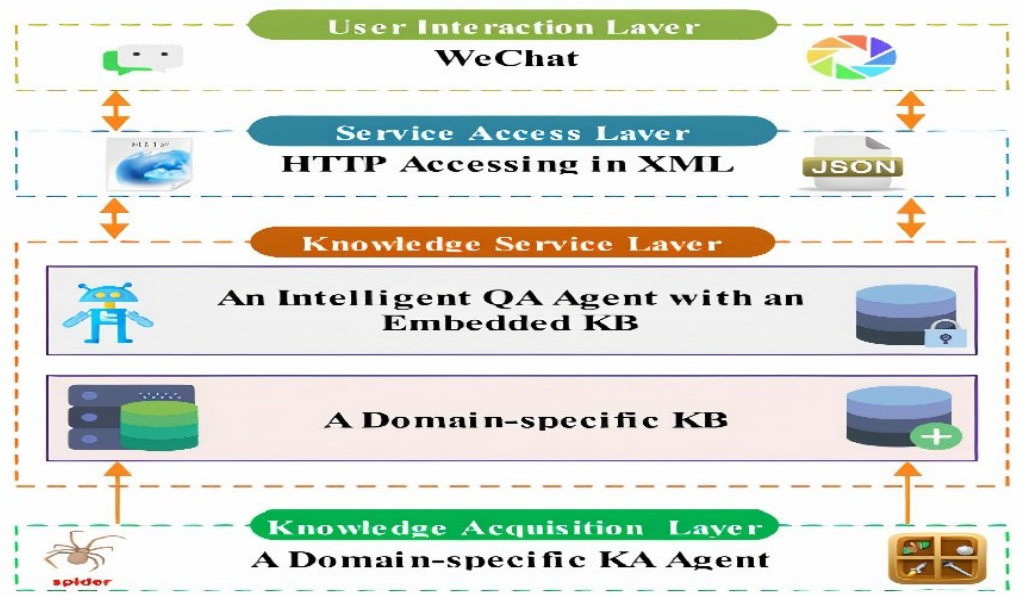

Fig. 4. Conceptual architecture of domain-specific Chabot proposed by Liu Qingtang \& al [26].

The 19 studies with components studies, target population and authors are summarized in Table 8 below:

Table 8.Studies with specific components

\begin{tabular}{|c|c|c|c|}
\hline Authors & Population & Methodology & Specific component \\
\hline Aqle \& al (2020) [22] & $\begin{array}{c}\text { visually } \\
\text { impaired } \\
\text { people VIP }\end{array}$ & $\begin{array}{c}\text { Quantitative \& } \\
\text { Qualitative }\end{array}$ & search engine \\
\hline $\begin{array}{c}\text { Arrue Myriam \& al.(2008) } \\
\text { [23] }\end{array}$ & PWD & $\begin{array}{c}\text { Quantitative \& } \\
\text { Prototype }\end{array}$ & search engine \\
\hline $\begin{array}{c}\text { Sitbon Laurianne \& al (2010) } \\
{[27]}\end{array}$ & $\begin{array}{c}\text { dyslexia } \\
\text { impairment }\end{array}$ & Experiment & $\begin{array}{c}\text { recherche } \\
\text { documentaire }\end{array}$ \\
\hline $\begin{array}{c}\text { Liu Qingtang \& al (2020) [26] } \\
{[25]}\end{array}$ & PWD & Quantitative & Chatbot \\
\hline $\begin{array}{c}\text { Calvo Rocío \& al (2017) [24] } \\
\text { [31] }\end{array}$ & PWD & Descriptive & Chatbot \\
\hline $\begin{array}{c}\text { Smutny Pavel \& al (2020) } \\
\text { Students } \\
\text { with } \\
\text { disabilities }\end{array}$ & Descriptive & Chatbot \\
\hline $\begin{array}{c}\text { Lister Kate \& al (2020) [28] } \\
\text { PWD }\end{array}$ & Review & Chatbot \\
\hline $\begin{array}{c}\text { Lidio Antonelli } \\
\text { Humberto \& al (2015) [29] }\end{array}$ & PWD & Case study & web menus \\
\hline $\begin{array}{c}\text { Estrada-Martínez Francisco J. } \\
\text { \& al (2020) [30] }\end{array}$ & PWD & $\begin{array}{c}\text { Systematic } \\
\text { Riterature } \\
\text { Review }\end{array}$ & Descriptive \\
\hline $\begin{array}{c}\text { Harper Simon \& al (2007) web } \\
\text { XHTML document }\end{array}$ \\
\hline
\end{tabular}




\begin{tabular}{|c|c|c|c|}
\hline $\begin{array}{c}\text { Montagud Mario \& al (2020) } \\
\text { [32] }\end{array}$ & hearing & Experiment & $\begin{array}{c}\text { customized and } \\
\text { synchronized } \\
\text { presentation of } \\
\text { subtitles }\end{array}$ \\
\hline $\begin{array}{c}\text { Giakoumis Dimitris \& al } \\
\text { (2014) [33] }\end{array}$ & PWD & Prototype & $\begin{array}{c}\text { Web Service } \\
\text { accessibility } \\
\text { assessment Framework } \\
\text { (WSaaF) }\end{array}$ \\
\hline $\begin{array}{c}\text { Seo Woosuk \& al (2021) [34] } \\
\text { (2019) [35] }\end{array}$ & VIP & Qualitative & YouTube video \\
\hline $\begin{array}{c}\text { Shoaib Muhammad \& al } \\
\text { VIP }\end{array}$ & Experiment & $\begin{array}{c}\text { auditory interfaces of } \\
\text { desktop applications }\end{array}$ \\
\hline $\begin{array}{c}\text { Pantula Muralidhar \& al } \\
\text { (2019) [36] }\end{array}$ & VIP & Quantitative & Audio descriptions \\
\hline $\begin{array}{c}\text { González María \& al (2015) } \\
\text { [37] } \quad \text { PWD }\end{array}$ & Descriptive & media player \\
\hline $\begin{array}{c}\text { Hughes Chris J. \& al (2020) } \\
\text { [38] }\end{array}$ & PWD & Qualitative & $360^{\circ}$ video players \\
\hline $\begin{array}{c}\text { Neerincx Mark A. \& al } \\
\text { (2009) [39] }\end{array}$ & PWD & Descriptive & Speech technologies \\
\hline
\end{tabular}

\section{DISCUSSION AND CONLUCSION}

Several limitations bounded the present review; we extracted references from different scientific databases; however, we faced technical problems with Scopus during our collection, which impacted the distribution of the score compared to the other scientific databases. An additional weakness related to our review is that Moroccan studies are hard to capture because they are scattered across various sources.

This systematic literature review identified 204 studies and aimed to explore and provide an overview of a state-of-the-art about digital accessibility with a particular focus on Moroccan studies. On the international scale, we notice that investigations could be divided into two groups. Some researchers carried out digital accessibility in all aspects, and others focused on specific elements and components about accessibility. They even focused on a particular type of disability or impairment. On the national scale, we detected a lack of descriptive and experimental research about digital accessibility in Morocco; only a few studies have been conducted compared to other countries. Thus further studies should be undertaken about digital accessibility involving people with disabilities.

\section{References}

1. T. Berners Lee. 1997. World Wide Web Consortium Launches International Program Office for Web Accessibility Initiative. Government, Industry, Research and Disability Organizations Join Forces to Promote Accessibility of the Web.

https://www.w3.org/Press/IPOannounce ( accessed 24 June 2021)

2. World Wide Web Consortium (W3C). Available at:

http://www. w3.org/

3. World Wide Web Consortium (W3C) Web Accessibility Initiative (WAI) Available at: 
https://www.w3.org/WAI/about/\#world-wide-web-consortium-w3c-web-accessibilityinitiative-wai

4. Introduction to Web Accessibility. Available at: https://www.w3.org/WAI/fundamentals/accessibility-intro/

5. Accessibility Easterseals Study on the Impact of COVID-19 on People with Disabilities Executive Summary \& Key Findings: May 2021.

6. Accessibility Guidelines (WCAG) Overview https://www.w3.org/WAI/standards-guidelines/wcag/

7. Web Content Accessibility Guidelines 1.0. Available at : https://www.w3.org/TR/WAI-WEBCONTENT/

8. Web Content Accessibility Guidelines 2.0. Available at: https://www.w3.org/TR/WCAG20/

9. Web Content Accessibility Guidelines 2.1. Available at: https://www.w3.org/TR/WCAG21/

10. Web Content Accessibility Guidelines 2.2. Working Draft Available at: https://www.w3.org/TR/WCAG22/

11. Accessibility Principles. Available at: https://www.w3.org/WAI/fundamentals/accessibility-principles/

12. Perceivable Principle WCAG 2.1. Available at: https://www.w3.org/TR/WCA21/\#perceivable

13. Operable Principle WCAG 2.1. Available at: https://www.w3.org/TR/WCAG21/\#operable

14. Understandable Principle WCAG 2.1. Available at: https://www.w3.org/TR/WCAG21/\#understandable

15. Robust Principle WCAG 2.1. Available at: https://www.w3.org/TR/WCAG21/\#robust

16. A. Moumen, «Séminaire sur la méthodologie de recherche \& guide des bonnes pratiques et techniques en communication, redaction et publication scientifique $\gg$.(2018)

17. Ministry of Solidarity, Social Development, Equality and Family. The National Disability Survey. Rabat, Morocco: 2014. Available at: https://social.gov.ma/wp-content/uploads/2021/04/ENPH-Rapport-Fr-BAT-OL-.pdf

18. the common charter for governmental websites Available at: http://www.egov.ma/sites/default/files/cc_2012_v1.pdf

19. I. Bousarhane, and N. Daoudi, «The Accessibility of Moroccan Public Websites: Evaluation of Three E-Government Websites ». Electronic Journal of E-Government 12 (1): pp65-79-pp65-79. (2014)

20. J. Ismaili, E. Ouazzani Ibrahimi. «Mobile Learning as Alternative to Assistive Technology Devices for Special Needs Students ». Education and Information Technologies 22 (3): 883-99 (2017) https://doi.org/10.1007/s10639-015-9462-9.

21. S. Boumaghzel, et M. I. Hafidi Alaoui, « La technologie éducative et handicap dans l'enseignement supérieur au Maroc» «Cas de l'université Med V ». Massalek Atarbya $\begin{array}{llllll}\text { Wa } & \text { Atakwine } & \text { volume } & 2 & \text { N1 } & \text { (2019) }\end{array}$ https://doi.org/10.48403/IMIST.PRSM/massalek-v2i1.19923 (accessed 01 February 2021).

22. A. Aqle, D. Al-Thani, and A. Jaoua, « Can Search Result Summaries Enhance the Web 
Search Efficiency and Experiences of the Visually Impaired Users? » Universal Access in the Information Society, November, 1-22. (2020)

https://doi.org/10.1007/s10209-020-00777-w.

23. M. Arrue, M. Vigo, and J. Abascal, «Web Accessibility Awareness in Search Engine Results ». Universal Access in the Information Society 7 (1): 103-16 (2008) https://doi.org/10.1007/s10209-007-0106-8.

24. C. Rocío, A. Iglesias and L. Castaño, «Evaluation of Accessibility Barriers and Learning Features in M-Learning Chat Applications for Users with Disabilities ». Universal Access in the Information Society 16 (3): 593-607 (2017). https://doi.org/10.1007/s10209-016-0484-x.

25. P. Smutny, and P. Schreiberova, "Chatbots for Learning: A Review of Educational Chatbots for the Facebook Messenger ». Computers \& Education 151 (juillet): 103862. (2020) https://doi.org/10.1016/j.compedu.2020.103862.

26. Q. Liu, J. Huang, L. Wu, K. Zhu, and S. Ba, « CBET: Design and Evaluation of a Domain-Specific Chatbot for Mobile Learning ». Universal Access in the Information Society 19 (3): 655-73 (2020) https://doi.org/10.1007/s10209-019-00666-x.

27. L. Sitbon, P. Bellot, P. Blache. «Vers une recherche d'information adaptée aux utilisateurs dyslexiques ». Document numerique Vol. 13 (1): 161-85. (2010)

28. K. Lister, T. Coughlan, F. Iniesto, N. Freear, et P. Devine. « Accessible Conversational User Interfaces: Considerations for Design » In W4A '20: Proceedings of the 17th International Web for All Conference, article no. 5, 1-11. (2020) https://doi.org/10.1145/3371300.3383343.

29. H. Lidio Antonelli, E. Adriano N. da Silva, et R. Pontin M. Fortes. «A Model-Driven Development for Creating Accessible Web Menus ». DSAI Procedia Computer Science 67:95-104. (2015) https://doi.org/10.1016/j.procs.2015.09.253.

30. Francisco J. Estrada-Martínez, José R. Hilera, S. Otón, et J. Aguado-Delgado.. «Semantic Web Technologies Applied to Software Accessibility Evaluation: A Systematic Literature Review ». Universal Access in the Information Society, octobre, 1-25. (2020) https://doi.org/10.1007/s10209-020-00759-y.

31. S. Harper, Y. Yesilada. "Web Authoring for Accessibility (WAfA) ». Journal of Web Semantics 5 (3): 175-79. (2007) https://doi.org/10.1016/j.websem.2007.05.001.

32. M. Montagud, F. Boronat, J. Pastor, D. Marfil. « Web-Based Platform for a Customizable and Synchronized Presentation of Subtitles in Single- and Multi-Screen Scenarios ». Multimedia Tools and Applications 79 (29): 21889-923. (2020) https://doi.org/10.1007/s11042-020-08955-x.

33. D. Giakoumis, K. Votis, et D. Tzovaras, «Introducing Web Service Accessibility Assessment Techniques through a Unified Quality of Service Context ». Service Oriented Computing and Applications 8 (2): 159-74. (2014) https://doi.org/10.1007/s11761-013-0135-5.

34. W. Seo, H. Jung, "Challenges and Opportunities to Improve the Accessibility of YouTube for People with Visual Impairments as Content Creators ». Universal Access in the Information Society (2021). https://doi.org/10.1007/s10209-020-00787-8.

35. M. Shoaib, I. Hussain, H T. Mirza, « Automatic Switching between Speech and NonSpeech: Adaptive Auditory Feedback in Desktop Assistance for the Visually Impaired ». Universal Access in the Information Society 19 (4): 813-23. (2019) 
https://doi.org/10.1007/s10209-019-00696-5.

36. M. Pantula, et K. S. Kuppusamy, « AuDIVA: A Tool for Embedding Audio

Descriptions to Enhance Video Accessibility for Persons with Visual Impairments ».

Multimedia Tools and Applications 78 (14): 20005-18. (2019)

https://doi.org/10.1007/s11042-019-7363-4.

37. M. González, L. Moreno, et P. Martínez, «Approach Design of an Accessible Media Player ». Universal Access in the Information Society 14 (1): 45-55. (2015) https://doi.org/10.1007/s10209-013-0342-z.

38. Chris J. Hughes, et M. Montagud, «Accessibility in $360^{\circ}$ Video Players ». Multimedia Tools and Applications, October, 1-28. (2020) https://doi.org/10.1007/s11042-020-10088-0.

39. M A. Neerincx, A H M. Cremers, J M. Kessens, D A. van Leeuwen, et K P. Truong. «Attuning Speech-Enabled Interfaces to User and Context for Inclusive Design:

Technology, Methodology and Practice ». Universal Access in the Information Society 8 (2): 109-22. (2009)

https://doi.org/10.1007/s10209-008-0136-x. 